\title{
D ivision in bacteria is determined by hyperstructure dynamics and membrane domains
}

\author{
Vic Norris $^{1, *}$ and Itzhak Fishov ${ }^{2}$ \\ ${ }^{1}$ Laboratoire des Processus Intégratifs Cellulaires, UPRESA CNRS 6037, Faculté des Sciences et Techniques, \\ Université de Rouen, F76821 Mont Saint Aignan Cedex, France \\ ${ }^{2}$ Department of Life Sciences, Ben-Gurion University of the Negev, POB 653, Be'er Sheva, Israel 84105
}

\begin{abstract}
No consensus exists for the nature of the mechanism responsible for creating the division site in the right place at the right time in bacteria. We have proposed that this mechanism depends on hyperstructures which constitute an intermediate level of organisation in cells. Non-equilibrium hyperstructures comprise the genes, mRNA, proteins and lipids required for a particular function, such as cell division, and certain of them assemble and disassemble during the cell cycle. We review the evidence for the hypotheses that, firstly, cell division involves proteolipid domains in the cytoplasmic membrane surrounding the nucleoids, secondly, these domains form part of hyperstructures and, thirdly, the key protein in cell division, FtsZ, is sequestered and released by glycolytic hyperstructures. We suggest experiments to test these hypotheses including those based on secondary ion mass spectrometry.
\end{abstract}

Keywords: interface, FtsZ, transertion, glycolysis, nucleoid, segregation

\section{INTRODUCTION}

The migration of the "tubulin-like" GTPase, FtsZ, from the cytoplasm to a site between the future daughter chromosomes is the earliest known stage of cell division in bacteria [1]. Polymerization of FtsZ from this site forms a ring of FtsZ around the cell [2] and recruits at least nine different proteins to a division complex, the so-called "divisome" or "septalsome" [3,4]; these proteins include the "actin-like" molecules FtsA [5], FtsI, FtsN, FtsQ, FtsK, FtsL and ZipA [6]. The nature of the events that lie upstream of FtsZ migration and polymerization remain elusive and cannot simply be attributed to the action of yet another protein without risking an infinite regression.

One approach to the problem of division is that of "nucleoid occlusion" in which the nucleoid would inhibit formation of a division site on the surrounding membrane (by an unknown mechanism) such that subsequent separation of the segregating nucleoids would allow this site to form between them [7, 8]; this would be consistent with the observed repression of peptidoglycan synthesis around the nucleoids [9]. There are other possibilities. It has been argued that certain genes, their products and associated ions and lipids interact to structure membranes and cytoplasm into hyperstructures [10] (see Fig. 1). Hyperstructures constitute a level intermediate between macromolecules and cells and correspond to the modules recently proposed to occupy a similar level in eukaryotic cells [11]. In searching for events upstream of FtsZ activation and the operation of the divisome, here we propose a hypothesis in which FtsZ is released by certain hyperstructures to be attracted by membrane domains produced by other hyperstructures.

\footnotetext{
*Author for correspondence. e-mail: vjn@univ-rouen.fr ; telephone: +332 3514 6908; fax: +3323514 7020 .
}

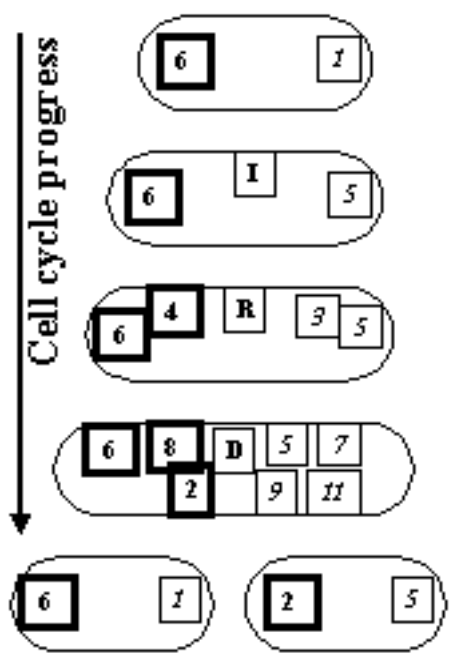

Figure 1. Cell cycle progress as a state cycle of hyperstructures. The membrane, the cytoplasm and the nucleoid are not homogeneous but are formed from an intermediate level of hyperstructures that may bring together particular genes, enzymes, lipids and ions to perform a particular function such as DNA replication or cell division [40]. Hyperstructures result from forces of lipid-protein and protein-protein interaction which structure the membrane into proteolipid domains [16], the effects of local concentrations of polymeric DNA-binding proteins and their sites which structure the cytoplasm into regions of different transcriptional, translational and enzymic activities [70], and forces of compaction and expansion which structure the nucleoid [14]. Rectangles represent non-equilibrium hyperstructures, each performing one function. Thin lines, odd numbers and italics correspond to hyperstructures with a common set of lipid preferences whilst thick lines, even numbers and normal font correspond to hyperstructures with a different set of preferences. I, initiation hyperstructure; $\mathbf{R}$, replication hyperstructure; $\mathbf{D}$, division hyperstructure. 


\section{HYPOTHESIS}

We propose that membrane domains formed by hyperstructures control bacterial division. This hypothesis is in five parts:

1. Proteolipid domains are created by the coupled transcription-translation-insertion of proteins into and through membranes (transertion). More specifically, this would be because nascent proteins being inserted into and through the membrane can be dynamically anchored via their mRNA to highly expressed genes. We propose that these proteins create membrane domains if they have specific lipid affinities (see Fig. 2).

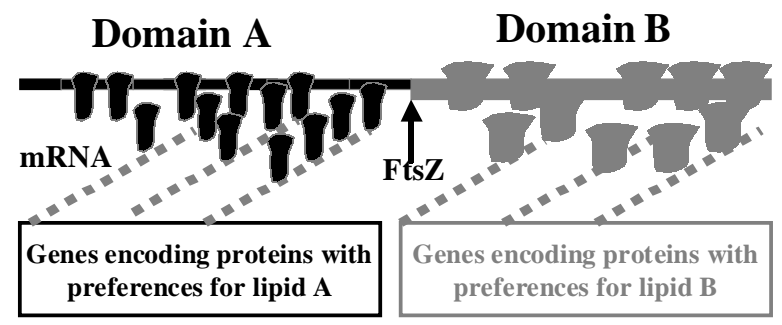

Figure 2. The coupled transcription, translation and insertion (transertion) of membrane and exported proteins plays a major rôle in the organization of membrane, cytoplasm and nucleoid that leads to the generation of hyperstructures $[10,16]$. The dynamics of hyperstructures results in the formation of membrane domains and an associated division hyperstructure that ensures division at the right time and place. One advantage of this hypothesis is its implication that the general physical chemistry and biochemistry of the cell are sufficient to explain cell cycle regulation with no absolute requirement for dedicated "motors" and "timers". The transertion of one set of membrane proteins tethers nascent proteins to the membrane and creates a proteolipid domain (black) adjacent to another set that creates a different domain (grey). FtsZ may be attracted to either the interface between them or to a specific domain. RNA polymerases and ribosomes are not shown.

2. The dynamics of these domains position and time FtsZ assembly between the nucleoids. We consider two possibilities for the nature of the site that attracts and activates FtsZ. FtsZ is attracted to either the interface between two different membrane domains or a newly formed septal domain. In the first case, each chromosome would be surrounded by a different proteolipid domain. In the second case, each chromosome would be surrounded by an identical proteolipid domain with a septal domain in a different proteolipid state between the chromosomes.

3. These domains are part of a compartmentation of the bacterial cell into hyperstructures. The idea is that the bacterial membrane and cytoplasm are structured into compartments, primarily in the form of non-equilibrium hyperstructures that assemble when needed and disassemble when no longer needed by the cell. Both assembly and disassembly are largely due to changes in the affinities of a hyperstructure's constituents for one another. These constituents may include a group of genes, their mRNA and the proteins encoded which come together at the same time in the same place to perform a particular function. Depending on the function in question, a non-equilibrium hyperstructure may include a proteolipid domain.

4. Fts $Z$ is released by the disassembly of certain hyperstructures to participate in division. During the period outside division, FtsZ does not diffuse freely as an inactive protein in the cytoplasm but contributes to the structural integrity of the cell by polymerizing and by associating with glycolytic enzymes into glycolytic hyperstructures.

5. Division itself is accomplished by a division hyperstructure. The genes encoding division enzymes, their mRNA and the enzymes themselves assemble into a division hyperstructure that carries out cell division. The assembly of this hyperstructure is governed in part by the dynamics of other hyperstructures. Factors that promote the formation of the division hyperstructure include the affinities of division proteins for one another, the binding of polymeric DNA-binding proteins to their sites in division genes, post-translational modifications to division proteins, and the release of FtsZ from other hyperstructures.

\section{THE CREATION OF MEMBRANE DOMAINS BY TRANSERTION}

Highly expressed genes encoding membrane and exported proteins are dynamically anchored to the membrane via their mRNA and nascent proteins, as proposed in the transertion (coupled transcriptiontranslation-insertion) model [12-14]. If these proteins have preferences for particular lipids, they may create proteolipid domains around the nucleoid that differ in proteolipid composition and structure from the membrane elsewhere in the cell [15]. It is predicted that blocking transcription or translation should disrupt the anchors between genes and membrane domains and hence disrupt the domains themselves. Such disruption of membrane dynamics can be revealed by a reporter of membrane viscosity such as diphenylhexatriene. The viscosity of Escherichia coli and Bacillus subtilis membranes was indeed reduced when protein synthesis was inhibited by chloramphenicol or puromycin, or when initiation of RNA synthesis was inhibited by rifampicin [16], treatments which effectively dissociate genes from membranes. Inhibition of RNA elongation by streptolydigin or induction of the stringent response by amino acid starvation did not reduce viscosity, consistent with these treatments "freezing" the transertion hyperstructures (and their associated domains) [16].

\section{MEMBRANE DOMAINS POSITION FTSZ POLIMERIZATION}

Current experimental results do not distinguish between a model in which there is an identical type of proteolipid 
domain around each nucleoid and a septal domain between them [17] and one in which there are different domains around each chromosome [15]. The truth may entail elements from both. In the latter case, as one domain forms around one developing daughter nucleoid, a different and complementary one forms around the other. This is due to the differentiation that occurs spontaneously in a system in which there is negative regulation in trans and positive regulation in cis [13]. Negative regulation in trans results from competition for expression with less than $10 \%$ of genes expressed at any one time in E. coli [18]; positive regulation in cis occurs because once a gene is out of the nucleoid being transcribed it is more accessible to RNA polymerase for further transcription. Conceivably, formation of the division hyperstructure could be nucleated by the resulting interface between the two domains, which may be expected to interact with the hydrophobic parts of proteins. There is already some evidence that such interfaces can attract a wide variety of proteins and even direct their self-assembly [19, 20]. FtsZ could be one of these proteins whose conformation is altered and which polymerize along the interface, helped by a high local concentration. Conformational changes in FtsZ affecting its hydrophobicity have been observed [21, 22]; moreover, FtsZ forms rings at phospholipid surfaces [23].

Evidence for domains in bacterial membranes has been obtained with many techniques. A lipophilic fluorescent probe, the styryl dye FM 4-64 [N-(3-triethylammoniumpropyl)-4-(6-(4-(diethylamino)phenyl) hexatrienyl) pyridinium dibromide], is often used as an indicator of the physicochemical state of membranes, whilst DAPI (4',6diamidino-2-phenylindole) is classically used to indicate the position of chromosomes. The simultaneous use of FM 4-64 and DAPI in vivo revealed dramatic differences in the fluorescence of the cytoplasmic membrane of $E$. coli with bands of different intensities at the poles, around the nucleoids and between them [24]. Significantly, a dark zone between the nucleoids is formed at the time when FtsZ migrates to the membrane. These zones may be related the large cardiolipin (CL) domains in the septal region and poles of $E$. coli visualized by use of the fluorescent dye, 10- $N$-nonylacridine orange, which binds specifically to CL [25]. Evidence consistent with domain formation guiding cell division has also been obtained using anthracene-labelled lipids, indicating a major change in lipid distribution during the cell cycle of Micrococcus luteus [26]. Minicells, which result from aberrant divisions occurring near the bacterial poles rather than in the centre, also reveal the considerable heterogeneity in lipid distribution in the membranes of E. coli, with 1.5 times the phosphatidylglycerol (PG) level and 0.75 times the phosphatidylethanolamine (PE) level of the rest of the bacterium [27]. Different but equally significant ratios were also obtained for Bacillus subtilis [28]. As well as these spatial differences in lipid distribution there are also temporal differences in composition [29] and in rates of lipid synthesis [30-32]. Given that proteolipid domains exist and determine the timing and positioning of division, perturbations of lipid composition should interfere with cell division. Fusions of the green fluorescent protein to ZipA and FtsZ were used to study their localization in a mutant of E. coli devoid of its principal phospholipid, PE [33]. Division was inhibited and ZipA and FtsZ formed spiral structures rather than the polymeric ring structures normally associated with division. These abnormal division structures were usually "correctly" localised between nucleoids, a finding apparently at odds with the idea that lipid domains are important in such localization. One explanation is that distinct proteolipid domains, based on the two other major phospholipids in E. coli, PG and CL, can still form around the chromosomes but give rise to a less attractive interface. These mutant results are therefore consistent with the idea that lipid domains direct division.

\section{COMPARTMENTATION IN BACTERIA}

The stalked and swarmer daughter cells that result from a division of the differentiating bacterium Caulobacter crescentus have very different patterns of gene expression and protein localization. ParAB nucleoid partitioning proteins, for example, are localized to the poles in this organism [34] as are the analogous SpoOJ proteins in B. subtilis [35]. The origins of replication (oriCs) are also localized to the poles in vegetatively growing $B$. subtilis [36] and in "non-differentiating" E. coli $[37,38]$. SeqA, which is involved in sequestering newly replicated oriC in E. coli, migrates from mid-cell to quarter and three quarter positions [39], and a SeqA hyperstructure has been proposed that would bring together the genes and the enzymes they encode to deliver the precursors of DNA directly to the replication complex [40]. The terminus of replication (terC) is localised at the pole opposite to oriC prior to initiation and migrates to mid-cell after initiation [38]. Remarkably, the Min complex, which has been implicated in both the selection and inactivation of division sites [41, 42], oscillates between extended polar regions of E. coli [43-45]. One possibility is that a Min hyperstructure is responsible for inactivating division sites and converting them into polar compartments [46] by acting as a phospholipid translocase that would mediate the distribution of specific phospholipids at the division site (V. Norris, G. Misevic and A. Oshima, submitted for publication).

Several proteins that are not directly implicated in the cell cycle also appear to be localised. For example, proteins involved in filamenting host cell actin cluster at the poles of Listeria monocytogenes [47] and Shigella flexneri [48] whilst complexes of inner membrane chemoreceptors and other chemotactic proteins cluster at the poles of E. coli where they form part of a chemotaxis hyperstructure [49, 50]. Compartmentation extends to a wide variety of multienzyme complexes, metabolons and hyperstructures [10, $51,52]$. For example, nonequilibrium hyperstructures may be responsible for the transport and metabolism of glucose [53] and for the assembly of ribosomes in nucleolar-like structures that could, along with transertion, play a major rôle in the partitioning of nucleoids $[54,55]$. 


\section{FTSZ AND GLYCOLYTIC HYPERSTRUC- TURES}

It is generally believed that for much of the cell cycle FtsZ exists in a monomeric and inactive form in the cytoplasm before migrating to the equator to become a polymer active in cell division. We call the first part of this belief into question: firstly, it is just an assumption that as such should be questioned; and, secondly, the related protein tubulin is used by eukaryotic cells for a variety of functions in addition to cell division and, given the parsimony of bacteria, it would be surprising if they were to waste the opportunities afforded by the presence of a tubulin-like protein in many thousands of copies per cell.

With the tubulin metaphor in mind, one evident rôle for FtsZ other than in cell division could be to contribute to the structural stability of the bacterial cell. Fine protofilaments of FtsZ running through the cytoplasm might help to hold cells together. Short filaments would be difficult to detect unequivocally as has been the case until recently for the actin-like filaments of $\mathrm{MreB}$ and $\mathrm{Mbl}$ in B.subtilis [56]. In fact high resolution immunofluorescence images of $E$. coli reveal a heterogeneous distribution of FtsZ with numerous foci [1] and another rôle for FtsZ could be proposed on the basis of the known association between eukaryotic tubulin and glycolytic enzymes. Tubulin and microtubules cosediment with many glycolytic enzymes including glucose-6-phosphate isomerase, aldolase, glyceraldehyde-3-phosphate dehydrogenase, phosphoglycerate kinase, lactate dehydrogenase and pyruvate kinase [57]. The $K_{d}$ values of 1-4 $\mu \mathrm{M}$ for the interaction of tubulin and microtubules with glyceraldehyde-3-phosphate dehydrogenase, pyruvate kinase and lactate dehydrogenase are in the range of the concentration of these enzymes in cells consistent with their association with microtubules in vivo. Furthermore, glyceraldehyde-3-phosphate dehydrogenase, lactate dehydrogenase and pyruvate kinase appear to generate networks by cross-linking microtubules [58]. These interactions are associated with enzymic activity such that drugs that bind to microtubules perturb glycolysis so consolidating the idea that glycolysis may be regulated in part by interactions between microtubules and glycolytic enzymes [59].

What would be the implications of an association between glycolytic enzymes and FtsZ? We have proposed elsewhere that increases in the affinities of the phosphotransferase system (PTS) transporters and successive enzymes for one another in the presence of their substrate sugar lead to the assembly of PTS-glycolytic hyperstructures [53]. Such non-equilibrium hyperstructures would disassemble in the absence of substrates, as indicated by a cellular automaton model [60]. Association of a PTS-glycolytic hyperstructure with FtsZ polymers would stabilize the hyperstructure against fluctuations in the supply of sugars. Such association may have another significance. It has been argued that the diversity of hyperstructures varies during the cell cycle and that in the run-up to the initiation of chromosome replication certain hyperstructures become stronger by attracting ever more of the cell's resources (such as the transcriptional and translational apparatus) whilst other hyperstructures are weakened and disappear [61]. PTS-glycolytic hyperstructures are amongst those that could become stronger in this way (depending on growth conditions) and that could continue to attract and sequester FtsZ. DNA replication could disrupt these hyperstructures both directly by interrupting transcription of the genes encoding the enzymes in the hyperstructure and indirectly by duplicating all genes and so allowing divergent gene expression of the two chromosomes [13]. In this scenario, temporary disruption of PTS-glycolytic hyperstructures by DNA replication would release FtsZ that could then participate in division. An alternative or complementary scenario is that the changing activity of the PTS/glycolytic hyperstructure directly leads to its own disassembly (for example, its capacity might exceed demand and lead to feedback inhibition). This would be consistent with the advance in divisions in synchronous cultures of $E$. coli induced by addition of the non-metabolizable glucose analogue $\alpha$ methylglucoside [62] and the delay induced by transfer to a rich growth medium [63].

Cyclic variations in the assembly/disassembly of PTSglycolytic hyperstructures might be related to the oscillations in glycolysis and in the rate of glucose uptake reported in numerous studies (for example $[64,65]$ ) since such oscillations could alter the affinities of PTS-glycolytic enzymes for one another [53]. These oscillations were found to have the same periodicity as cell division with a sharp decrease in the rate of glucose consumption at the start of division and a minimal glycogen content during mid-cycle. It is furthermore conceivable that extensive networks of dynamic hyperstructures may have characteristic frequencies of vibrations that emit and receive electromagnetic energy in the $\mathrm{GHz}$ range [10]. Synchronization of such vibrations to a single mode might lead to a set of hyperstructures becoming the equivalent of a giant oscillating dipole [66]. Such a mode might signal that the cell possesses the sets of hyperstructures required for division into viable daughters and the giant oscillation would then result in the release of FtsZ by some hyperstructures and its recruitment by others. Significantly, exposure to specific $\mathrm{GHz}$ frequencies produces a partial division synchrony in yeast and decreases the growth rate of E. coli $[67,68]$.

\section{A DIVISION HYPERSTRUCTURE}

Cell cycle specific expression of division genes could, in principle, trigger the assembly of a division hyperstructure. Such expression occurs in $C$. crescentus and requires phospholipid synthesis [69]. In E. coli, however, division genes seem to be expressed constitutively as the bacterial cell grows: hardly any evidence exists for cyclical synthesis of division proteins. According to the model developed here, these genes are expressed in different parts of the cell during the build-up to division (that is, during 
chromosome replication). Then the membrane triggers the first, key step in cell division by creating a site-either a specific domain or an interface between domains - that attracts and activates FtsZ. Other proteins such as ZipA may also be attracted to the site. The transertion process then dynamically anchors $f t s Z$ and other division genes to the site. Subsequently, assembly of the division hyperstructure occurs due to a synergy between several candidate processes. Firstly, the affinities of division proteins for one another could help bring them together as proposed for the PTS enzymes [53]. Secondly, DNAbinding proteins may bind to sites in division genes to recruit them to the developing division hyperstructure. Polymeric proteins capable of binding to specific sites on DNA can indeed create high local concentrations of both proteins and sites [70]. Thirdly, differences in the modification or turnover of division proteins, according to their localization inside or outside the hyperstructure, could also facilitate its assembly. For example, acylation of FtsA [71] could play a rôle in its localization. Fourthly, FtsZ might be released to join the developing division hyperstructure by the disassembly or redistribution of glycolytic hyperstructures caused by DNA replication.

The formation of the division hyperstructure would entail the fts (filamenting temperature sensitive) genes encoding proteins implicated in division and the genes responsible for the synthesis of peptidoglycan such as mur (murein) coming together to deliver their products at the right place at the right time. Such formation would be favoured by a clustering of these genes on the chromosome, a clustering that does indeed occur. 16 genes, including ftsL, ftsI, murE, murF, mraY, murD, fts $W$, murG, murC, $d d l, f t s Q, f t s A$, and $f t s Z$, lie together in a cluster at the 2 minute position on the chromosome. The recent observation of the localization of the cell division protein, FtsQ, into foci underpins the proposal that this protein localization may be due to the co-localization of $f t s Q$ and neighbouring genes into just such a hyperstructure [72]. There is also evidence for the differential localization of penicillin-binding proteins, some of which are responsible for elongation of the peptidoglycan load-bearing layer and others for its invagination [73]. Consistent with this, the number of molecules of the major enzyme in cell wall elongation, PBP2, is reduced five-fold in minicell membranes [74]. Under conditions in which the expression of the genes in a division hyperstructure is reduced, other hyperstructures may be able to take the place of the division hyperstructure in the cytoplasm and so further reduce the expression of division genes. This may explain the fivefold reduction in FtsZ levels in an L-form of E. coli, in which peptidoglycan synthesis is seriously perturbed [75]. The division hyperstructure would facilitate invagination by increasing peptidoglycan synthesis both generally (by higher metabolic efficiency) and locally at the septum adjacent to the hyperstructure. Such increases have indeed been observed [76].

Division of the differentiating bacterium, $C$. crescentus, results in swarmer and stalk cells that have similar lipid compositions [77] which may seem difficult to reconcile with a rôle for proteolipid domains in the division of this bacterium. In fact, there are at least two possible explanations. Firstly, the proteolipid domains in the pre-divisional cell have compositional differences that are scrambled during the act of cell division. Secondly, these domains are physically different due to major differences in transcriptional activity (and hence transertion) and in the nature of the presumed hyperstructures in the future stalk and swarmer cells; it may be significant that the rate of phospholipid synthesis is very different in stalk and swarmer cells [77].

In many conditions in which bacteria such as E. coli filament, division may still occur towards one end of the filament to yield cells of normal size (but see [78]) that are often anucleate $[79,80]$. Moreover, certain filamentous mutants can have groups of FtsZ rings in long nucleoidfree gaps [81]. How could a division site be positioned other than between segregating nucleoids? One possibility is that hyperstructures in the pole of the filament create membrane domains with interfaces that attract and activate FtsZ by default in the absence of a proper division hyperstructure. The correct positioning of FtsZ rings in anucleate cells [82] may be due to the existence of hyperstructures comprising only lipids and proteins that allow membrane domains to form, albeit slowly, in the absence of nucleoids. Reciprocally, if FtsZ responds to an interface, an interface may be created by FtsZ itself but, again, slowly. In freshly germinating spores of $B$. subtilis with unperturbed intracellular processes, FtsZ rings form over the nucleoid at an early stage of replication [83]. Conceivably, hyperstructures and domains could already be present in the spore such that only limited growth is needed for a division hyperstructure to form at a preexisting interface.

\section{TESTING THE HYPOTHESIS}

There are several predictions of the hyperstructure model as applied to cell division:

1. The creation of domains by transertion could be observed by using lipophilic fluorescent dyes [24, 25] in a system of unilamellar liposomes in which membrane proteins are synthesized via an in vitro 'Zubay' system [84].

2. The positioning of FtsZ by membrane domains could be tested by forming lipid domains in a LangmuirBlodgett apparatus, adding FtsZ, transferring to mica and inspecting with atomic force microscopy [85].

3. Many genes involved in cell division and wall synthesis should, along with their products, be localized to a division hyperstructure. Testing this directly with conventional techniques is not easy at present since it requires the co-localization of such disparate elements as proteins, mRNA, genes and lipids at the $50 \mathrm{~nm}$ scale. In secondary ion mass spectrometry, a section of biological material is subjected to a beam of ions that pulverizes it to release 
secondary ions that are filtered by mass spectrometry to allow an image to be obtained [86]. Recent developments in this technique provide resolution at the scale required and allow detection of isotopically marked probes to proteins and nucleic acids.

4. FtsZ should interact with glycolytic enzymes. Sedimentation and microscopy studies similar to those performed with eukaryotic tubulin and eukaryotic enzymes could reveal such interactions. In addition, conditions in which FtsZ polymerization is perturbed, as in an $f t s Z$ temperature sensitive mutant grown at the non-permissive temperature, may also perturb glycolysis.

\section{DISCUSSION}

Formation and separation of membrane domains around the nucleoids during their replication would have the advantage of creating the division site in the right place at the right time. We have argued that these domains are intimately associated with non-equilibrium hyperstructures, each performing a particular function, that compete with one another for DNA-binding proteins, RNA polymerase and ribosomes (and, indeed, FtsZ itself) and hence for existence in the membrane and cytoplasm [10]. In this scenario, growing cells that are not replicating their DNA devote an increasing quantity of their resources to an increasingly limited set of hyperstructures [61]; DNA replication, by disrupting these hyperstructures and allowing others to form, enables cells to restore hyperstructure diversity. Then these hyperstructures spontaneously segregate within the cell such that cell division generates daughter cells that have different sets of hyperstructures and hence different phenotypes (Fig. 1). In this process, the bacterial population as a whole gains a controlled diversity of phenotypes. Cells can usefully be considered as autocatalytic networks [87] and computer modelling has shown that growth and division segregates different autocatalytic networks [88] (V. Norris and M. Demarty, manuscript in preparation). Here, we have argued that the dynamics of hyperstructures may create membrane domains around the chromosomes via transertion, that these domains may position the site of cell division, and that FtsZ, liberated from its role in PTSglycolytic hyperstructures, may participate in a division hyperstructure. Finally, it should be noted that the existence of a hyperstructure in which division genes are brought together to be expressed together would both concentrate and target their products to the division site and so have the advantage of favouring assembly of a multi-protein septal machine or divisome.

\section{ACKNOWLEDGEMENTS}

We are very grateful to Arieh Zaritsky and Conrad Woldringh for many helpful comments, and Ben de Kruijff for encouragement.

\section{REFERENCES}

1. Den Blaauwen, T., Buddelmeijer, N., Aarsman, M. E. G., Hameete, C. M. \& Nanninga, N. Timing of FtsZ assembly in Escherichia coli. J. Bacteriol. 181 (1999) 5167-5175.

2. Bi, E. \& Lutkenhaus, J. FtsZ ring structure associated with division in Escherichia coli. Nature 354 (1991) 161-164.

3. Holland, I. B. Genetic analysis of the E. coli division clock. Cell 48 (1987) 361-362

4. Nanninga, N. Morphogenesis of Escherichia coli. Microbiol. Mol. Biol. Rev. 62 (1998) 110-129.

5. van Den Ent, F. \& Lowe, J. Crystal structure of the cell division protein FtsA from Thermotoga maritima. EMBO J. 19 (2000) 5300-5307

6. Hale, C. A. \& de Boer, P. A. J. Recruitment of ZipA to the septal ring of Escherichia coli is dependent on FtsZ and independent of FtsA. J. Bacteriol. 181 (1999) 167-176.

7. Woldringh, C. L., Mulder, E., Valkenburg, J. A. C., Wientjes, F. B., Zaritsky, A. \& Nanninga, N. Role of the nucleoid in the toporegulation of division. Res. Microbiol. 141 (1990) 39-49.

8. Woldringh, C. L., Mulder, E., Huls, P. G. \& Vischer, N. O. E. Toporegulation of bacterial division according to the nucleoid occlusion model. Res. Microbiol. 142 (1991) 309-320.

9. Mulder, E. \& Woldringh, C. L. Autoradiographic analysis of diaminopimelic acid incorporation in filamentous cells of Escherichia coli: repression of peptidoglycan synthesis around the nucleoid. J. Bacteriol. 173 (1991) 4751-4756.

10. Norris, V., Alexandre, S., Bouligand, Y., Cellier, D., Demarty, M., Grehan, G., Gouesbet, G., Guespin, J., Insinna, E., Le Sceller, L., Maheu, B., Monnier, C., Grant, N., Onoda, T., Orange, N., Oshima, A., Picton, L., Polaert, H., Ripoll, C., Thellier, M., Valleton, J.-M., Verdus, M.-C., Vincent, J.-C., White, G. \& Wiggins, P. Hypothesis: hyperstructures regulate bacterial structure and the cell cycle. Biochimie 81 (1999) 915-920.

11. Hartwell, L. H., Hopfield, J. J., Leibler, S. \& Murray, A. W. From molecular to modular cell biology. Nature (Lond.) 402 (6761 Suppl.) (1999) C47-52.

12. Lynch, A. S. \& Wang, J. C. Anchoring of DNA to the bacterial cytoplasmic membrane through co-transcriptional synthesis of polypeptides encoding membrane proteins or proteins for export : a mechanism of plasmid hypernegative supercoiling in mutants deficient in DNA topoisomerase I. J. Bacteriol. 175 (1993) 1645-1655.

13. Norris, V. \& Madsen, M. S. Autocatalytic gene expression occurs via transertion and membrane domain formation and underlies differentiation in bacteria: a model. J. Mol. Biol. 253 (1995) 739-748.

14. Woldringh, C. L., Jensen, P. R. \& Westerhoff, H. V. Structure and partitioning of bacterial DNA determined by a balance of compaction and expansion forces? FEMS Microbiol. Lett. 131 (1995) 235-242. 
15. Norris, V. Hypothesis: chromosome separation in E. coli involves autocatalytic gene expression, transertion and membrane domain formation. Mol. Microbiol. 16 (1995) 1051-1057.

16. Binenbaum, Z., Parola, A. H., Zaritsky, A. \& Fishov, I. Transcription- and translation-dependent changes in membrane dynamics in bacteria: testing the transertion model for domain formation. Mol. Microbiol. 32 (1999) 1173-1182.

17. Norris, V. Phospholipid domains determine the spatial organization of the Escherichia coli cell cycle : the membrane tectonics model. J. Theor. Biol. 154 (1992) 91-107.

18. Stickle, D. F., Vossen, K. M., Riley, D. A. \& Fried, M. G. Free DNA concentration in E. coli estimated by an analysis of competition for DNA binding proteins. J. Theor. Biol. 168 (1994) 1-12.

19. Netz, R. R., Andelman, D. \& Orland, H. Protein adsorption on lipid monolayers at their coexistence region. J. Phys. II (Paris) 6 (1996) 1023-1047.

20. Baneyx, G. \& Vogel, V. Self-assembly of fibronectin into fibrillar networks underneath dipalmitoyl phosphatidylcholine monolayers: role of lipid matrix and tensile forces. Proc. Natl Acad. Sci.USA 96 (1999) 12518-12523.

21. Voskuil, J. L. \& Nanninga, N. How does FtsZ find its location? Microbial Drug Resistance 2 (1996) 5561.

22. Yu, X.-C. \& Margolin, W. Inhibition of assembly of bacterial cell division protein FtsZ by the hydrophobic dye 5,5'-Bis-(8-anilino-1-naphthalenesulfonate). J. Biol. Chem. 273 (1998) 10216-10222.

23. Alexandre, S., Colé, G., Coutard, S., Monnier, C., Norris, V., Margolin, W., Yu, X. \& Valleton, J.-M. Interaction of FtsZ protein with a DPPE Langmuir film. Colloids Surf. B (2001) in press.

24. Fishov, I. \& Woldringh, C. Visualization of membrane domains in Escherichia coli. Mol. Microbiol. 32 (1999) 1166-1172.

25. Mileykovskaya, E. \& Dowhan, W. Visualization of phospholipid domains in Escherichia coli by using the cardiolipin-specific fluorescent dye 10-N-nonyl acridine orange. J. Bacteriol. 182 (2000) 1172-1175.

26. Welby, M., Poquet, Y. \& Tocanne, J.-F. The spatial distribution of phospholipids and glycolipids in the membrane of the bacterium Micrococcus luteus varies during the cell cycle. FEBS Lett. 384 (1996) 107-111.

27. Goodell, E. W., Schwartz, U. \& Teather, R. M. Cell envelope composition of Escherichia coli K12 : a comparison of the cell poles and the lateral wall. Eur. J. Biochem. 47 (1974) 567-572.

28. Shohayeb, M. \& Chopra, I. Composition of membranes from whole cells and minicells of Bacillus subtilis. J. Gen. Microbiol. 131 (1985) 345-354.

29. Mozharov, A. D., Shchipakin, V. N., Fishov, I. L. \& Evtodienko, Y. V. Changes in the composition of membrane phospholipids during the cell cycle of E. coli. FEBS Lett. 186 (1985) 103-106.

30. Pierucci, O. Phospholipid synthesis during the cell division cycle of Escherichia coli. J. Bacteriol. 138 (1979) 453-460.

31. Carty, C. E. \& Ingram, L. O. Lipid synthesis during the Escherichia coli cell cycle. J. Bacteriol. 145 (1981) 472-478.

32. Joseleau-Petit, D., Kepes, F., Peutat, L., D’Ari, R. \& Kepes, A. DNA replication initiation, doubling of rate of phospholipid synthesis, and cell division in Escherichia coli. J. Bacteriol. 169 (1987) 3701-3706.

33. Mileykovskaya, E., Sun, Q., Margolin, W. \& Dowhan, W. Localization and function of early cell division proteins in filamentous Escherichia coli cells lacking phosphatidylethanolamine. J. Bacteriol. 180 (1998) 4252-4257.

34. Mohl, D. A. \& Gober, J. W. Cell cycle-dependent polar localization of chromosome partitioning proteins in Caulobacter crescentus. Cell 88 (1997) 675-684.

35. Lin, D. C.-H., Levin, P. A. \& Grossman, A. D. Bipolar localization of a chromosome partition protein in Bacillus subtilis. Proc. Natl Acad. Sci., U.S.A. 94 (1997) 4721-4726.

36. Webb, C. D., Teleman, A., Gordon, S., Straight, A., Belmont, A., Lin, D. C.-H., Grossman, A. D., Wright, A. \& Losick, R. Bipolar localization of the replication origin regions of chromosomes in vegetative and sporulating cells of B. subtilis. Cell 88 (1997) 667-674.

37. Gordon, G. S., Sitnikov, D., Webb, C. D., Teleman, A., Straight, A., Losick, R., Murray, A. W. \& Wright, A. Chromosome and low copy plasmid segregation in $\mathrm{E}$. coli: visual evidence for distinct mechanisms. Cell 90 (1997) 1113-1121.

38. Niki, H. \& Hiraga, S. Polar localization of the replication origin and terminus in Escherichia coli nucleoids during chromosome partitioning. Genes Dev. 12 (1998) 1036-1045.

39. Onogi, T., Niki, H., Yamazoe, M. \& Hiraga, S. The assembly and migration of SeqA-Gfp fusion in living cells of Escherichia coli. Mol. Microbiol. 31 (1999) 1775-1782.

40. Norris, V., Fralick, J. \& Danchin, A. A SeqA hyperstructure and its interactions direct the replication and sequestration of DNA. Mol. Microbiol. 37 (2000) 696-702.

41. Teather, R. M., Collins, J. F. \& Donachie, W. D. Quantal behavior of a diffusible factor which initiates septum formation at potential division sites in E. coli. J. Bacteriol. 118 (1974) 407-413.

42. de Boer, P. A. J., Crossley, R. E. \& Rothfield, L. I. A division inhibitor and a topological specificity factor coded for by the minicell locus determine the proper placement of the division site in Escherichia coli. Cell 56 (1989) 641-649.

43. Raskin, D. M. \& de Boer, P. A. Rapid pole-to-pole oscillation of a protein required for directing division to the middle of Escherichia coli. Proc. Natl Acad. Sci., U.S.A. 96 (1999) 4971-4976.

44. Hu, Z. \& Lutkenhaus, J. Topological regulation of cell division in Escherichia coli involves rapid pole to pole oscillation of the division inhibitor MinC under 
the control of MinD and MinE. Mol. Microbiol. 34 (1999) 82-90.

45. Fu, X., Shih, Y. L., Zhang, Y. \& Rothfield, L. I. The MinE ring required for proper placement of the division site is a mobile structure that changes its cellular location during the Escherichia coli division cycle. Proc. Natl Acad. Sci., U.S.A. 98 (2001) 980-985.

46. Norris, V.\& Fishov, I. Hypothesis: membrane domains and hyperstructures control bacterial division. Biochimie 83 (2001) 91-98.

47. Kocks, C., Hellio, R., Gounon, P., Ohayon, H. \& Cossart, P. Polarized distribution of Listeria monocytogenes surface protein ActA at site of directional actin assembly. J. Cell Sci. 105 (1993) 699-710.

48. Goldberg, M. B., Barzu, O., Parsot, C. \& Sansonetti, P. J. Unipolar localization and ATPase activity of IcsA, a Shigella flexneri protein involved in intracellular movement. J. Bacteriol. 175 (1993) 2189-2196.

49. Maddock, J. R. \& Shapiro, L. Polar location of the chemoreceptor complex in the Escherichia coli cell. Science 259 (1993) 1717-1723.

50. Stock, J. \& Levit, M. Signal transduction: hair brains in bacterial chemotaxis. Current Biol. 10. (2000) R11-4.

51. Velot, C., Mixon, M. B., Teige, M. \& Srere, P. A. Model of a quinary structure between Krebs TCA cycle enzymes: a model for the metabolon. Biochemistry 36 (1997) 14271-14276.

52. Hoppert, M. \& Mayer, F. Principles of macromolecular organization and cell function in Bacteria and Archaea. Cell Biochem. Biophys. 31 (1999) 247-283.

53. Norris, V., Gascuel, P., Guespin-Michel, J., Ripoll, C. \& Saier Jr., M. H. Metabolite-induced metabolons: the activation of transporter-enzyme complexes by substrate binding. Mol. Microbiol. 31 (1999) 1592-1595.

54. Woldringh, C. L., Zaritsky, A. \& Grover, N. B. Nucleoid partitioning and the division plane in Escherichia coli. J. Bacteriol. 176 (1994) 6030-6038.

55. Zaritsky, A., Woldringh, C. L., Pritchard, R. H. \& Fishov, I. (2000) in Microbial Diversity., Kluwer Academic., Dordrecht.

56. Jones, L. J., Carballido-Lopez, R. \& Errington, J. Control of cell shape in bacteria. Helical, actin-like filaments in Bacillus subtilis. Cell 104 (2001) 913-922.

57. Walsh, J. L., Keith, T. J. \& Knull, H. R. Glycolytic enzyme interactions with tubulin and microtubules. Biochim. Biophys. Acta 999 (1989) 64-70.

58. Volker, K. W., Reinitz, C. A. \& Knull, H. R. Glycolytic enzymes and assembly of microtubule networks. Comp. Biochem. Physiol. B Biochem. Mol. Biol. 112 (1995) 503-514.

59. Lloyd, P. G. \& Hardin, C. D. Role of microtubules in the regulation of metabolism in isolated cerebral microvessels. Am. J. Physiol. 277 (1999) C1250-1262.

60. Le Sceller, L., Ripoll, C., Demarty, M., Cabin-Flaman, A., Nyström, T., Saier Jnr., M. \& Norris, V. Modelling bacterial hyperstructures with cellular automata. Interjournal Paper 366 (2000) http://www.interjournal.org

61. Norris, V., Demarty, M., Raine, D., Cabin-Flaman, A.
\& Le Sceller, L. Hypothesis: hyperstructures regulate initiation in Escherichia coli and other bacteria. Biochimie (2001) in press.

62. Fishov, I. (1994) in What is Controlling Life? (Gnaiger, E., Gellerich, F.N., Wyss, M., eds), pp. 221-225, Innsbruck University Press.

63. Kepes, F. \& Kepes, A. Postponement of cell division by nutritional shift-up in Escherichia coli. J. Gen. Microbiol. 131 (1985) 677-685.

64. Planutis, K. S., Planutiene, M. V., Lazareva, A. V., Sel'kov, E. E. \& Evtodienko, Y. V. Polyglucose content in the cell and the rate of glucose consumption during synchronous growth of Escherichia coli. Biochem. Biophys. Res. Comm. 109 (1982) 583-587.

65. Shchipakin, V. N. \& Evtodienko, Y. V. Glycolytic intermediate levels in the cell cycle of sea urchin eggs and bacteria. Comp. Biochem. Physiol. 77B (1984) 245-247.

66. Fröhlich, H. Long range coherence and energy storage in biological systems. Int. J. Quant. Chem. 42 (1968) 641-649.

67. Norris, V. \& Hyland, G. J. Do bacteria "sing"? Mol. Microbiol. 24 (1997) 879-880

68. Hyland, G. J. Non-thermal bioeffects induced by lowintensity microwave irradiation of living systems. Engng Sci. Edu. J. (December 1998) 261-269.

69. Brassinga, A. K., Gorbatyuk, B., Ouimet, M. C. \& Marczynski, G. T. Selective cell cycle transcription requires membrane synthesis in Caulobacter. EMBO J. 15 (2000) 702-709.

70. Revet, B., von Wilcken-Bergmann, B., Bessert, H., Barker, A. \& Müller-Hill, B. Four dimers of $\lambda$ repressor bound to two suitably spaced pairs of $\lambda$ operators form octamers and DNA loops over large distances. Current Biol. 9 (1999) 151-154.

71. Sanchez, M., Valencia, A., Ferrandiz, M.-J., Sandler, C. $\&$ Vicente, $M$. Correlation between the structure and biochemical activities of FtsA, an essential cell division protein of the actin family. EMBO J. 13 (1994) 4919-4925.

72. Buddelmeijer, N., Aarsman, M. E. G., Kolk, A. H. J., Vicente, M. \& Nanninga, N. Localisation of cell division protein FtsQ by immunofluorescence microscopy in dividing and non-dividing cells of Escherichia coli. J. Bacteriol. 180 (1998) 6107-6116.

73. Leidenix, M. J., Jacoby, G. H., Henderson, T. A. \& Young, K. D. Separation of Escherichia coli penicillin-binding proteins into different membrane vesicles by agarose electrophoresis and sizing chromatography. J. Bacteriol. 171 (1989) 5680-5686.

74. Buchanan, C. E. Topographical distribution of penicillin-binding proteins in the Escherichia coli membrane. J. Bacteriol. 145 (1981) 1293-1298.

75. Onoda, T., Enokizono, J., Kaya, H., Oshima, A., Freestone, P. \& Norris, V. Effects of calcium and calcium chelators on growth and morphology of Escherichia coli L-form NC-7. J. Bacteriol. 182 (2000) 1419-1422.

76. Wientjes, F. B. \& Nanninga, N. Rate and topography 
of peptidoglycan synthesis during cell division in Escherichia coli: concept of a leading edge. J. Bacteriol. 171 (1989) 3412-3419.

77. Mansour, J. D., Henry, S. \& Shapiro, L. Differential membrane phospholipid synthesis during the cell cycle of Caulobacter crescentus. J. Bacteriol. 141 (1980) 262-269.

78. Mulder, E. \& Woldringh, C. L. Actively replicating nucleoids influence positioning of division sites in Escherichia coli filaments forming cells lacking DNA. J. Bacteriol. 173 (1989) 4751-4756.

79. Jaffé, A., D’Ari, R. \& Norris, V. SOS-independent coupling between DNA replication and cell division in E. coli. J. Bacteriol. 165 (1986) 66-71.

80. Cook, W. R. \& Rothfield, L. I. Nucleoid-independent identification of cell division sites in Escherichia coli. J. Bacteriol. 181 (1999) 1900-1905.

81. Yu, X. C. \& Margolin, W. FtsZ ring clusters in min and partition mutants: role of both the Min system and the nucleoid in regulating FtsZ ring localization. Mol. Microbiol. 32 (1999) 315-326.

82. Sun, Q., Yu, X.-C. \& Margolin, W. Assembly of the FtsZ ring at the central division site in the absence of the chromosome. Mol. Microbiol. 29 (1998) 491-503.
83. Harry, E. J., Rodwell, J. \& Wake, R. G. Co-ordinating DNA replication with cell division in bacteria: a link between the early stages of a round of replication and mid-cell Z ring assembly. Mol. Microbiol. 33 (1999) 33-40.

84. Zubay, G. In vitro synthesis of protein in microbial systems. A. Rev. Gen. 7 (1973) 267-298.

85. Alexandre, S., Derue, V., Garah, S., Monnier, C., Norris, V. \& Valleton, J.-M. Submolecular structures in dipalmytoylphosphatidylethanolamine LangmuirBlodgett films observed by scanning force microscopy. J. Colloid Interface Sci. 227 (2000) 585-587.

86. Thellier, M., Ripoll, C., Quintana, C., Sommer, F., Chevallier, P. \& Dainty, J. Physical methods to locate metal atoms in biological systems. Methods Enzymol. 227 (1993) 535-586.

87. Kauffman, S. (1996) At Home in the Universe, the Search for the Laws of Complexity. London: Penguin.

88. Segre, D., Ben-Eli, D. \& Lancet, D. Compositional genomes: prebiotic information transfer in mutually catalytic noncovalent assemblies. Proc. Natl Acad. Sci., U.S.A. 97 (2000) 4112-4117. 